\title{
Vulnerabilidade e riscos Socioecológicos: uma perspectiva integrada dos riscos na Região de Guaratiba (Rio de Janeiro - Brasil)
}

\section{Vulnerability and socio-ecological risks: an integrated perspective of risks in Guaratiba region (Rio de Janeiro - Brazil)}

Maria Luciene da Silva Lima1

Alexandro Solórzano
Luiz Felipe Guanaes Rego
Marcelo Motta de Freitas
Bianca Pereira Alvim Porto
Bi

\begin{abstract}
Palavras-chave: Gestão da Paisagem Geoprocessamento Lógica Fuzzy
\end{abstract}

\begin{abstract}
Resumo
$\mathrm{Na}$ região de Guaratiba, ao longo de quase cinco séculos de ocupação e consequentes processos de transformação da paisagem, cenários ecológicos tornaram-se áreas produtivas, residenciais e de transição urbana. Essa historicidade constitui elemento-chave para a compreensão das vulnerabilidades locais e riscos associados. Nesse sentido, no âmbito da gestão da paisagem, sob uma abordagem integradora de vulnerabilidade e riscos, temos como objetivo mapear e analisar as vulnerabilidades e riscos socioecológicos na área de estudo. $\mathrm{O}$ trabalho se estruturou na investigação da história de uso, ocupação e transformação da paisagem, na identificação de áreas vulneráveis, bem como na classificação dos riscos socioecológicos. Assim, estabeleceram-se três etapas metodológicas para tal compreensão: (1) análise dos processos históricos de uso e ocupação das terras em Guaratiba; (2) delimitação das Unidades Socioecológicas da Paisagem (USEP), com o intuito de compreender os níveis atuais de heterogeneidade da área estudada; e por fim, (3) a modelagem e categorização dos riscos socioecológicos identificados. Essa análise, baseada na técnica de geoprocessamento conhecida como lógica fuzzy, levou ao entendimento de uma classificação socioecológica dos riscos, reconhecendo que tais fenômenos só podem ser compreendidos a partir da presença humana perante a pertinência de eventos que possam ferir os grupos expostos. Como resultado desta investigação, quatro das seis unidades de paisagem delimitadas apresentaram locais com tendência a riscos: USEP 2, USEP 4, USEP 5 e USEP 6. Tais áreas sugerem riscos socioecológicos do tipo físico relacionados a dinâmicas geomorfológicas (deslizamentos e de enchentes) e de saúde ambiental.
\end{abstract}

${ }^{1}$ Pontifícia Universidade Católica do Rio de Janeiro - PUC-Rio. PPG em Geografia, Rio de Janeiro, RJ, Brasil.marialucienelima@gmail.com

2 Pontifícia Universidade Católica do Rio de Janeiro - PUC-Rio. Departamento de Geografia e Meio Ambiente, Rio de Janeiro, RJ, Brasil. alexandrosol@gmail.com

3 Pontifícia Universidade Católica do Rio de Janeiro - PUC-Rio. Departamento de Geografia e Meio Ambiente, Rio de Janeiro, RJ, Brasil. luizfelipeguanaes@gmail.com

${ }^{4}$ Pontifícia Universidade Católica do Rio de Janeiro - PUC-Rio. Departamento de Geografia e Meio Ambiente, Rio de Janeiro, RJ, Brasil. marcelomotta@puc-rio.br

5 Pontifícia Universidade Católica do Rio de Janeiro - PUC-Rio. PPG em Geografia, Rio de Janeiro, RJ, Brasil.biancapap@gmail.com 
Keywords:

Landscape Management

Geoprocessing

Fuzzy Logic

\begin{abstract}
Through almost five centuries of occupation and the resulting processes of landscape transformation, ecological scenarios in the neighborhood of Guaratiba have become areas of production, residence, and urban transition. This historicity is a key element to understand local vulnerabilities and associated risks. Thus, within the scope of landscape management and under an integrative approach of vulnerabilities and risks, our objective in this study is to map and analyze socioecological vulnerabilities and risks in the study area. Research was structured on i) investigating the history of landscape use, occupation and transformation, ii) identifying vulnerable areas, and iii) classifying socio-ecological risks. Three methodological steps were used: (1) analysis of historical processes of land use and occupation in Guaratiba; (2) delimitation of Socio-ecological Landscape Units (SELU) in order to understand current levels of heterogeneity in the study area; and (3) modeling and characterization of identified socio-ecological risks. Based on the geoprocessing technique known as fuzzy logic, analysis led to a socioecological classification of risks, recognizing that such phenomena can only be understood by examining human presence in face of the relevance of events which can harm exposed groups. The investigation showed that four out of six delimitated landscape units have points on which there is a tendency of risks: SELU 2, SELU 4, SELU 5, and SELU 6. These areas suggest socio-ecological risks of the physical type, related to geomorphologic (landslides and floods) and environmental health dynamics.
\end{abstract}

\section{INTRODUÇÃO}

A perspectiva da vulnerabilidade interage com a dimensão do habitar social, contexto que condiciona as populações diante de eventos de exposição à vida ou pertinências consequentes aos riscos de caráter socioecológicos (BRASIL, 2007; CARVALHO, 2010; LAVELL et al, 2012; LAYRARGUES, 2012; MANDAROLA JÚNIOR, 2014; PORTO, 2012; SAITO et al, 2015; VEYRETE, 2015). Tal paradigma motivou a investigação sobre os espaços onde tais eventos ocorrem, por meio do mapeamento de áreas potenciais a riscos categorizados como socioecológicos na Região de Guaratiba, localizada no município do Rio de Janeiro (RJ Brasil).

Essa região que foi desbravada ainda no século XVI (MANSUR, 2008; 2011; 2016), estabeleceu a partir de então um processo de transição das paisagens guaratibenses que revelou ao longo do tempo uma história de lutas fundiárias por meio dessas mudanças de cenários ecológicos para áreas produtivas, áreas de residências e de transição urbana. A região atravessou períodos econômicos que marcaram a história do Rio de Janeiro passando por ciclos de alta produtividade agrícolas e pecuárias e posterior declínio (MANSUR, 2008, 2011, 2016; MOTA, 2009). Conjunturas essas que levaram a significativas transformações nos processos de uso e ocupação e alteraram as relações socioecológicas locais.

Essas alterações nos espaços ecológicos e nos domínios territoriais proporcionaram a formação de núcleos habitacionais, tonando-se um elemento-chave para compreensão das vulnerabilidades locais e riscos associados (PORTO, 2012).

Nesse atual contexto de ordenamento territorial, em alguns locais, frente aos mais recentes projetos de expansão urbana da cidade do Rio de Janeiro, são discutidos os processos de urbanização os quais sujeitam o habitar a constantes conflitos de ordens ambiental e econômica, fazendo da antiga área rural do município uma nova área de interesse especulativo público e privado.

Buscando a compreensão dos contextos vulneráveis e de riscos, se existem e onde estariam localizados, neste estudo que é desdobramento de pesquisa de mestrado, o objetivo foi mapear e analisar a vulnerabilidade e risco socioecológico a partir da compreensão das dinâmicas espaciais locais para identificação dessas áreas e respectivas classificações.

Foi realizada a pesquisa no sistema hidrográfico do rio do Portinho, contemplando os bairros de Barra de Guaratiba e parte do bairro de Guaratiba, localizados no município do Rio de Janeiro, cumprindo as etapas metodológicas de revisão de literaturas que subsidia a discussão sobre os processos de vulnerabilidade e riscos socioecológicos; uma segunda etapa de delimitação de Unidades Socioecológicas da Paisagem (USEP) da área de estudo, para uma interpretação que possibilitou o entendimento da distribuição espacial dos elementos físicos, ecológicos e sociais da paisagem estudada e sua heterogeneidade, frente aos atuais processos de uso e ocupação das terras que definem tal paisagem; e por fim, a modelagem e classificação dos riscos socioecológicos com base na sistematização de técnicas de geoprocessamento 
e validação das análises empíricas desde os trabalhos de campo exploratórios e entrevistas com grupos focais.

Toda essa sistematização permitiu avaliar as vulnerabilidades e os riscos socioecológicos a partir de modelagem e caracterização das USEPs, uma abordagem integradora de diferentes aspectos, considerando a saúde ambiental, a geomorfologia e os aspectos humanos e sociais da população atingida.

Nesse sentido, entende-se esse diagnóstico como positivo por sublinhar a importância de políticas democráticas e participativas no ordenamento territorial e gestão da paisagem na região.

\section{PROCEDIMENTOS METODOLÓGICOS}

\section{Caracterização da Área de Estudo}

A área de estudo se localiza na Zona Oeste da cidade do Rio de Janeiro, entre as latitudes $22^{\circ} 55^{\prime} 00^{\prime} \mathrm{S}$ e $23^{\circ} 05^{\prime} 00^{\prime}$ 'S e longitudes $43^{\circ} 35^{\prime} 00^{\prime} \mathrm{W}$ e $43^{\circ} 30^{\prime} 00^{\prime \prime W}$ (Figura 1) e contempla os bairros de Barra de Guaratiba e parte do bairro de Guaratiba, além de parte dos territórios de tutela estadual do Parque Estadual da Pedra Branca (setor Ilha de Guaratiba) e Reserva Biológica Estadual de Guaratiba.

A área compreende $47,31 \mathrm{~km}^{2}$, repleta de biodiversidade atlântica, planícies de ambientes lacustres e maciço rochoso (Serra Geral de Guaratiba/ maciço da Pedra Branca).

$\mathrm{O}$ rio do Portinho, que dá nome ao sistema hidrográfico selecionado para área de estudo, nasce em torno da altitude de $220 \mathrm{~m}$ e deságua no Canal do Bacalhau, percorrendo $14 \mathrm{~km}$ da nascente à foz.

Figura 1 - Localização da Área de Estudo no Município do Rio de Janeiro (RJ - Brasil)

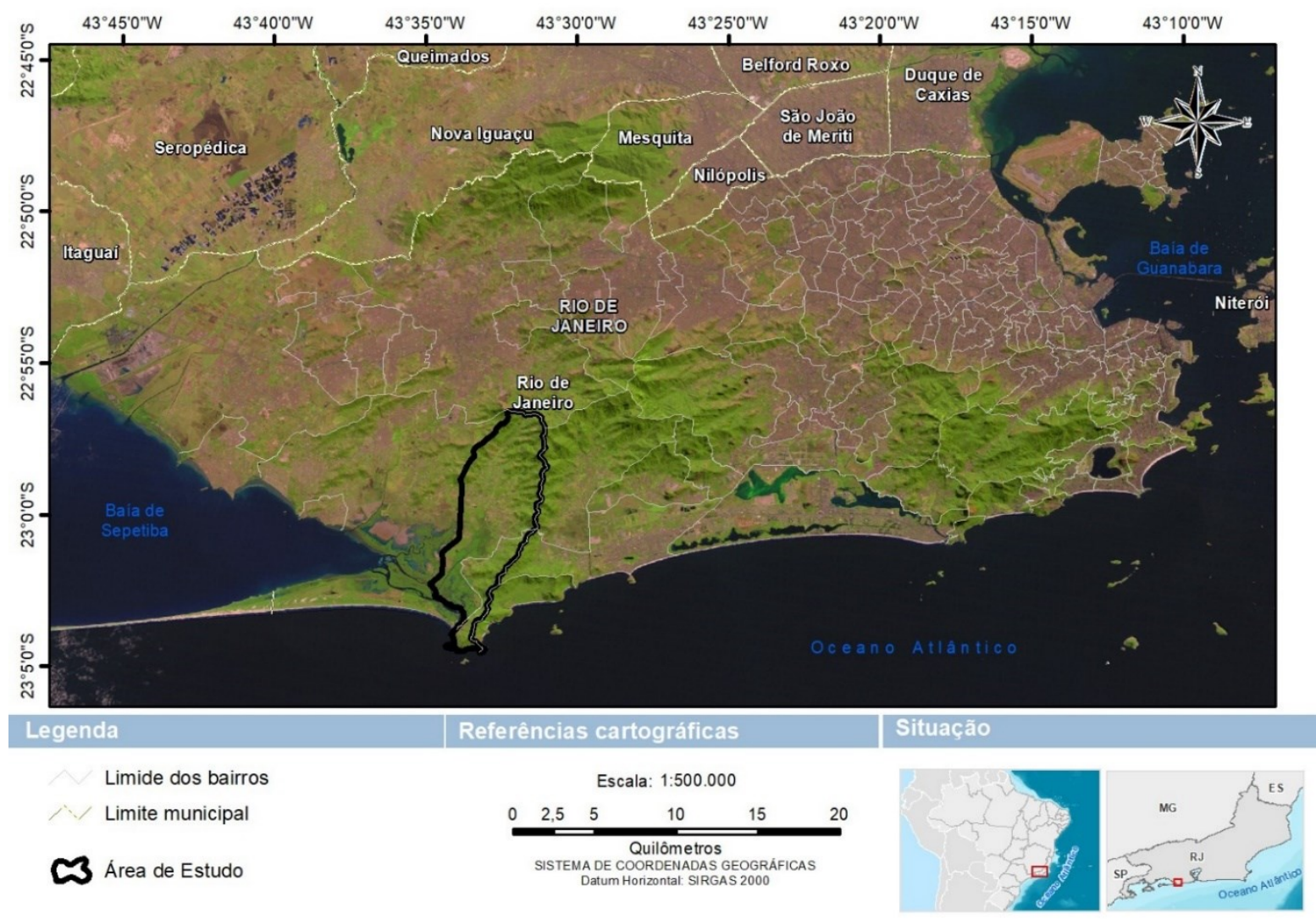

Fonte: Lima (2017). 
Guaratiba é o bairro com maior cobertura vegetal de Mata Atlântica (SMAC, 2011) na cidade do Rio de Janeiro, portanto, uma potencialidade paisagística para a região onde a economia local é baseada em atividade como o ecoturismo, gastronomia de pescado e forte interesse imobiliário.

O uso e a ocupação das terras na área estudada apresentam predominância de Floresta Ombrófila densa submontana e montana em estágio secundário de sucessão (inicial, intermediário e avançado), formações de manguezal, campos salinos (Apicum), vegetação arbóreo-arbustiva e outras formações antropogênicas, incluindo áreas de produção de banana e espécies ornamentais.

A amplitude topográfica ocorre entre $0 \mathrm{e}$ $680 \mathrm{~m}$ na vertente nordeste do sistema hidrográfico e apresenta uma morfologia que se destaca pelas unidades geomorfológicas de planícies fluviais e fluviomarinhas (0-20m), colinas isoladas (entre 20-100m), morros (100$200 \mathrm{~m}$ ) e serras (altitude superiores a 200m) nos maciços costeiros e interiores (INEA, 2011).

As formas de acúmulo de fluxos (terrenos planos) correspondem a $51 \%$ da área de estudo, com significativa porção de ocupação urbana nesse contexto, especialmente, ao longo do eixo viário $(\mathrm{E}-\mathrm{W})$.

Os grupos geológicos correspondem a formações Quaternárias de Sedimentos Fluviais e Pré-cambrianas das unidades Granodioríticas, Rio Negro e Rochas Graníticas (REIS; MANSUR, 1995), terrenos pertencentes ao Gráben da Guanabara (FERNANDEZ, 2012).

Nas áreas de relevo acidentado, predominam os Argissolos Vermelho-Amarelos, que são solos minerais bem intemperizados, muito evoluídos, com textura média argilosa ou por vezes tendendo a pedregosa, derivados dos gnaisses e granitos que formam o substrato dessa região. Vale destacar que são solos pertencentes a uma classe cujas características de suscetibilidade à erosão são consideráveis, podendo promover retenção de água bem como descontinuidade hidráulica, agravando a ocorrência de ravinas e voçorocas.

Nas regiões de baixas declividades há ocorrência de relevo plano a ondulado, onde predominam Gleissolos, ambiente este, submetido ao regime das marés. Esses solos estão condicionados a ambientes de encharcamento durante boa parte do ano; devido a essas características esses solos são conhecidos vulgarmente de "solos moles". Também é possível observar solos arenosos nas porções de restinga e solos indiscriminados de mangues (EMBRAPA, 2013; INEA, 2010).

Esse encharcamento estacional, é devido aos
Planossolos, cuja característica hidromórfica é responsável pela formação de lençol d'água sobreposto, áreas contidas na delimitação do aquífero de Guaratiba e ambientes de mangue. Situação essa que caracteriza uma sensibilidade no sistema ecológico, devido ao aspecto de pouco desenvolvimento do material pedogenético, além de questões geotécnicas referentes às habitações do local, circunstâncias que criam condições de vulnerabilidade para ocupação nessas áreas por grupos sociais, ou seja, pela exposição de riscos relativos à inundação.

Outra característica que denota importância são as áreas protegidas de tutela estadual na região, as quais cobrem em torno de $74 \%$ do sistema hidrográfico do rio do Portinho e cobertura restante de $26 \%$ sem tutela de proteção jurídica. Contudo, $100 \%$ da área de estudo está contida no mapeamento da Reserva da Biosfera da Mata Atlântica (RBMA), contexto esse que expressa importância significativa para um modelo de gestão integrada, sustentável e participativa dos recursos naturais locais.

\section{Materiais e Métodos}

A etapa inicial da pesquisa consistiu em levantamento bibliográfico para estabelecimento das abordagens conceituais realizada com apoio de diferentes publicações técnicas e acadêmicas e sites oficiais de instituições públicas.

$\mathrm{Na}$ etapa de levantamento de dados, foram adquiridos dados geográficos georreferenciados para as análises geoespaciais e elaboração de mapas (dados vetoriais em formato shapefile e imagens de satélite), a partir de websites institucionais e cedidos por departamentos de órgãos públicos. As imagens de Satélite utilizadas correspondem ao sendor Landsat 8 (2015) com resolução espacial de $30 \mathrm{~m}$, e Ortofotos (2015) com resolução espacial de 10m.

Foram realizados dois trabalhos de campo para obtenção de dados primários com uso de GPS para aquisição de pontos de interesse observados em campo, fotografias, entrevistas não estruturadas que auxiliaram nas análises geoespaciais, qualificação e descrições dos resultados apresentados.

Todos os dados geográficos foram projetados para o Sistema de Referências UTM 23S, Datum SIRGAS 2000.

As entrevistas não-estruturadas, foram realizadas com a participação de um líder comunitário e, a partir dele, outros informantes na condução dessas entrevistas. De maneira complementar, participamos de uma oficina com um grupo de moradores das localidades de 
Araçatiba, Olaria e Rua dos Guimarães. Essa etapa nos auxiliou no resgate das impressões dos moradores sobre os processos de uso e ocupação e risco local. As conversas não-estruturadas abordaram questões, tais como: Nessa localidade existe algum tipo de risco e qual seria a natureza desse evento? Há rios/canais próximos daqui? Costumam originar enchentes? Há enchentes? De qual natureza? Há registros de doenças como dengue, leptospirose ou outro tipo?

A seguir uma representação do esquema metodológico desta pesquisa (Figura 2):

Figura 2 - Esquema metodológico da pesquisa.

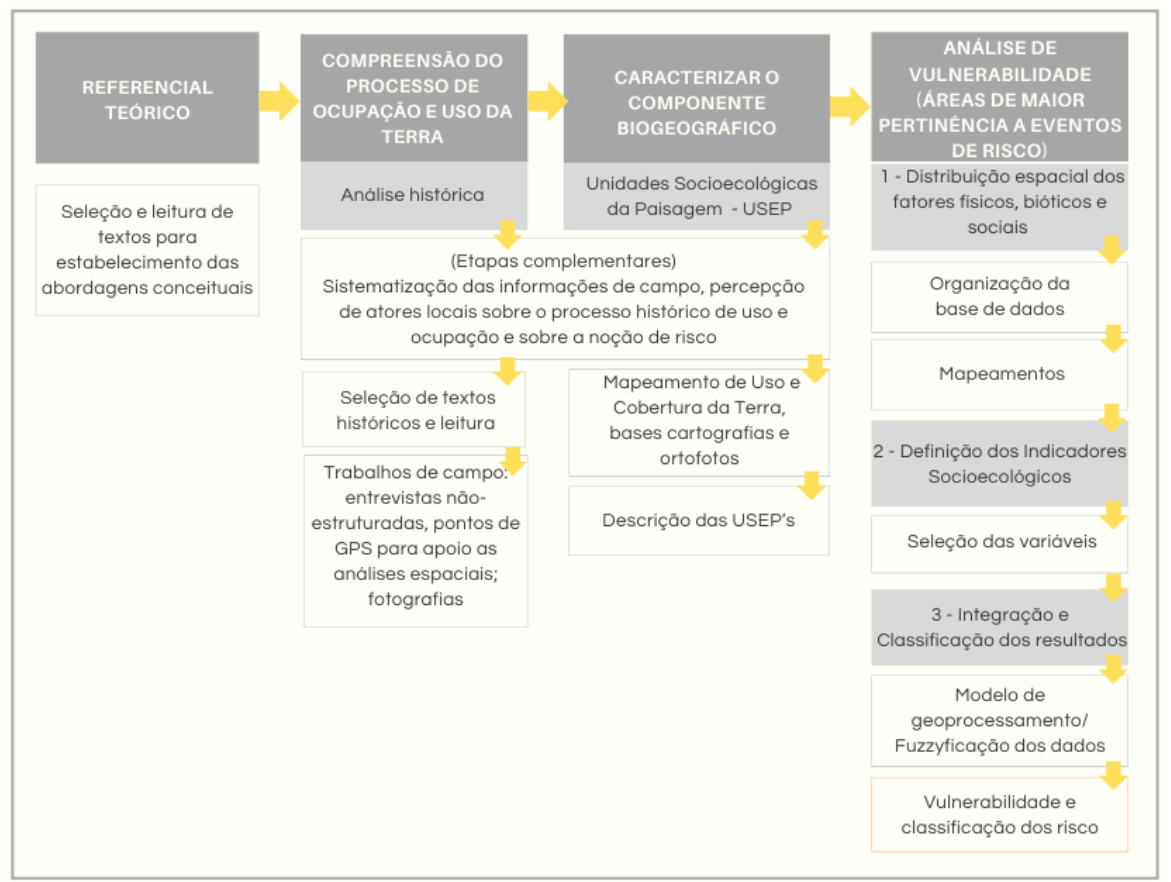

Fonte: Adaptado de Lima (2017).

\section{Delimitação das Unidades Socioecológicas da Paisagem}

A considerar a historicidade do lugar para uma respectiva interpretação da paisagem (SOLÓRZANO et al 2016), além da noção de vulnerabilidade e risco apresentada por Porto (2012), cuja ideia de risco conflui no encontro entre tempo, lugar e pessoas, corrobora, portanto, para essa interpretação socioecológica dos riscos.
Sob essa perspectiva, dividir a área de estudo em unidades, Unidades Socioecológicas da Paisagem - USEP, nos proporcionou um entendimento sob a percepção local, de acordo com os processos históricos reconhecidos para a área estudada e dinâmicas específicas em cada área.

Para uma melhor compreensão dessa etapa, segue abaixo o fluxograma explicativo de delimitação das Unidades Socioecológicas da Paisagem (Figura 3): 
Figura 3 - Fluxograma de trabalho para delimitação das Unidades Socioecológicas da Paisagem (USEPs).

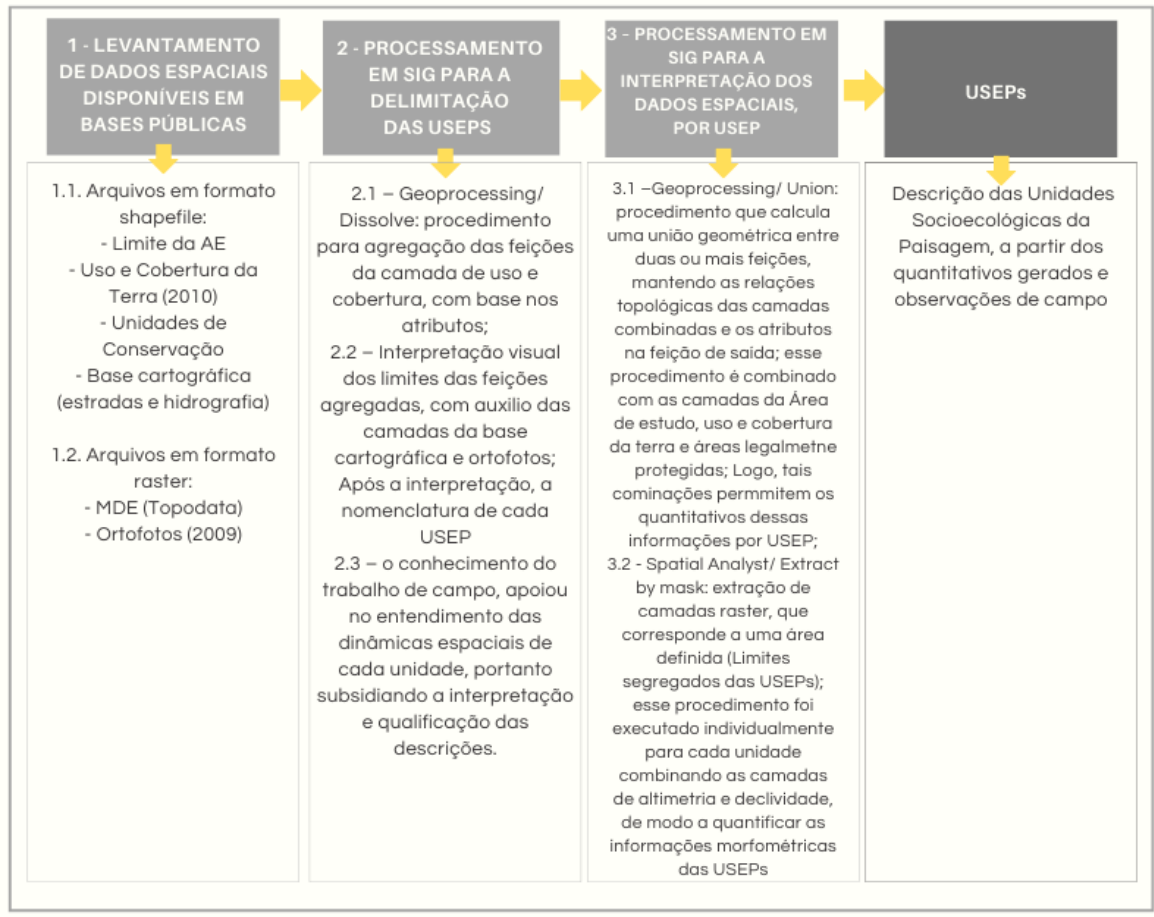

Fonte: Adaptado de Lima (2017).

Modelo de geoprocessamento: Análise de vulnerabilidade e classificação das áreas de risco socioecológico

A modelagem de sistemas ambientais se caracteriza em procedimentos metodológicos que considera a abordagem integrada na tentativa de identificar ou compreender determinados eventos ou fenômenos espaciais (CHRISTOFOLETTI, 1999). O autor aponta tais perspectivas sobre análises ambientais, a considerar complexidades dos sistemas analisados e seus componentes com importância da abordagem holística para a compreensão da organização espacial dos elementos físicos e (cor)relações entre eles.

Nesse sentido, as perguntas espaciais são a chave para resolução de problemas sobre a ótica geoespacial, na qual os procedimentos para uma modelagem ambiental devem ser organizados sistematicamente para subsidiar novos planos de informação temáticos.

A análise de vulnerabilidade e determinação de áreas de risco é baseada numa análise multicritérios que requer conhecer as áreas e situações favoráveis à ocorrência de determinados eventos. Logo, no processo de modelagem, estabelecem-se algumas etapas, tais como: 1) definir o problema; 2) elencar variáveis; 3) determinar os valores das variáveis elencadas (e ponderar quando possível); 4) reclassificar os dados (adequação dos planos de informação); 5) combinar as camadas; e 6) analisar os resultados.

Para atender aos objetivos desta pesquisa, que inclui a pergunta espacial: "Onde se localizam as áreas vulneráveis com maior pertinência aos riscos relacionados?", propomos um tipo de análise multicritério Fuzzy, que se fundamenta na teoria de conjuntos. A análise fornece técnicas para avaliar as inacurácias dos dados discretos, diminuindo efeitos de não pertinência espacial à categorização, a partir de dados contínuos (ZADEH, 1965; 1978).

Os procedimentos Fuzzy representam "os limites espaciais entre duas ou mais classes que são representadas por zonas transitórias onde os valores da variável são distribuídos de forma contínua." (FERREIRA, 2014, p. 286). Ainda sobre esse procedimento, o autor esclarece como são determinadas as áreas de maior e menor pertinência aos fenômenos analisados. Para as áreas-núcleo, consideradas de maior pertinência, os pixels se apresentam de maneira mais homogênea devido às afinidades determinadas pelos objetos dessa classe; para as áreas definidas como região limítrofe, ou zona transicional, apresentam-se características com menores afinidades, portanto, com menor pertinência ao fenômeno analisado.

A seguir no Quadro 1, são apresentadas as variáveis usadas no modelo de geoprocessamento, para indicação de áreas vulneráveis, assim como a justificativa para a escolha dessas Variáveis. 
Quadro 1: Seleção e descrição das variáveis utilizadas na modelagem

\begin{tabular}{|c|c|c|c|}
\hline $\begin{array}{l}\text { Variáveis } \\
\text { Selecionadas }\end{array}$ & Descrição & Justificativa & Fonte \\
\hline 1 - Declividade & $\begin{array}{l}\text { Representa áreas de } \\
\text { declives de } 0^{\circ}-20^{\circ} \text {, } \\
20^{\circ}-30^{\circ} \text { e }>30^{\circ}\end{array}$ & $\begin{array}{l}\text { Áreas de alto declive sugerem atenção } \\
\text { em relação aos processos de ocupação; } \\
\text { tais agrupamento foram definidos } \\
\text { qualitativamente }\end{array}$ & $\begin{array}{l}\text { SRTM 30m, } \\
\text { Topodata }\end{array}$ \\
\hline $\begin{array}{l}2 \text { - Morfologia } \\
\text { das encostas }\end{array}$ & $\begin{array}{l}\text { Representa Terrenos } \\
\text { côncavos, convexos e } \\
\text { planos }\end{array}$ & $\begin{array}{l}\text { A morfologia da paisagem é um } \\
\text { indicador importante no entendimento } \\
\text { dos processos de ocupação }\end{array}$ & $\begin{array}{l}\text { Mapeamento } \\
\text { integrado de } \\
\text { áreas de alta } \\
\text { declividade, } \\
\text { cavidades } \\
\text { analisadas a } \\
\text { partir do SRTM } \\
\text { e curvas de nível }\end{array}$ \\
\hline 3 - Solos & 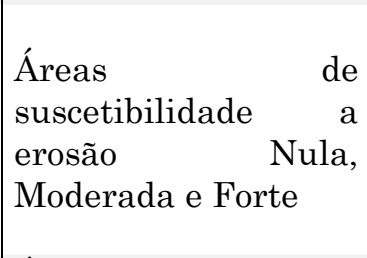 & $\begin{array}{l}\text { As classes de solos com maior } \\
\text { suscetibilidade à erosão, combinadas } \\
\text { com outros fatores físicos, mediante } \\
\text { eventos de forte chuva, podem favorecer } \\
\text { eventos geomorfológicos } \\
\text { (escorregamento). }\end{array}$ & $\begin{array}{l}\text { Solos - } \\
\text { Indicadores } \\
\text { Ambientais do } \\
\text { Estado do Rio de } \\
\text { Janeiro - INEA, } \\
2010\end{array}$ \\
\hline $\begin{array}{l}4 \text { - Cobertura } \\
\text { vegetal e uso } \\
\text { da terra }\end{array}$ & $\begin{array}{lr}\text { Áreas } & \text { antrópicas } \\
\text { agrícolas, } & \text { Áreas } \\
\text { antrópicas } & \text { não } \\
\text { agrícolas, } & \text { Formação } \\
\text { florestal, campestres, } \\
\text { formações } & \text { pioneiras, } \\
\text { água } & \end{array}$ & $\begin{array}{l}\text { Os processos de uso e ocupação são } \\
\text { importantes no entendimento dos riscos, } \\
\text { pois revelam o conhecimento dos lugares } \\
\text { onde há ocupação. }\end{array}$ & SMAC (2011) \\
\hline
\end{tabular}

Fonte: Lima (2017).

O modelo proposto apresentará áreas de maior pertinência a determinados riscos, a partir da combinação das camadas participantes.

A classificação dos riscos socioecológicos corresponderá aos resultados da análise fuzzy, ou seja, da combinação das camadas reclassificadas espacialmente e análise qualitativa das evidências observadas nos trabalhos de campo, que permitiram analisar e qualificar essas áreas.
A partir das etapas de: 1 - definição das variáveis; 2 - reclassificação dos atributos e transformação dos dados; 3 - definição dos níveis de pertinência; 4 - combinação das camadas; e 5 - análise dos resultados, no Quadro 2 explicamse essas etapas em fluxo de trabalho e modelo conceitual, cujos procedimentos foram executados em na interface model builder, no software ARCGIS 10.4. 
Quadro 2 - Modelo Conceitual: procedimentos executados para geração das áreas de vulnerabilidade

\begin{tabular}{|c|c|c|c|c|}
\hline \multicolumn{5}{|c|}{1 - Classificação e padronização das variáveis } \\
\hline Ferramenta & \begin{tabular}{c|c}
$\begin{array}{c}\text { Spatial Analyst / } \\
\text { Reclassify }\end{array}$ \\
\end{tabular} & \multicolumn{2}{|c|}{$\begin{array}{c}\text { Spatial Analyst / } \\
\text { Reclassify }\end{array}$} & $\begin{array}{c}\text { Spatial Analyst / } \\
\text { Reclassify }\end{array}$ \\
\hline Input & uso & \multicolumn{2}{|c|}{ solos } & MorfologiaEncostas \\
\hline Parâmetro & ordenar valores & \multicolumn{2}{|c|}{$\begin{array}{l}\text { ordenar valores das classes de } \\
\text { erosão }\end{array}$} & ordenar valores \\
\hline Output & Reclass_uso & \multicolumn{2}{|c|}{ Reclass_solos } & Reclass_MorfoE \\
\hline Ferramenta & Spatial Analyst / Float & \multicolumn{2}{|c|}{ Spatial Analyst / Float } & Spatial Analyst / Float \\
\hline Input & Reclass_uso & \multicolumn{2}{|c|}{ Reclass_solos } & Reclass_MorfoE \\
\hline Parâmetro & - & \multicolumn{2}{|c|}{-} & - \\
\hline Output & Float_uso & \multicolumn{2}{|c|}{ Float_solos } & Float_MorfoE \\
\hline Ferramenta & Spatial Analyst / Divide & \multicolumn{2}{|c|}{ Spatial Analyst / Divide } & Spatial Analyst / Divide \\
\hline Input & Float_uso & \multicolumn{2}{|c|}{ Float_solos } & Float_MorfoE \\
\hline Parâmetro & 10 & \multicolumn{2}{|c|}{10} & 10 \\
\hline Output & Divide_uso & \multicolumn{2}{|c|}{ Divide_solos } & Divide_MorfoE \\
\hline \multicolumn{5}{|c|}{2 - Definição dos graus de pertinência } \\
\hline Ferramenta & $\begin{array}{c}\text { Spatial Analyst / Fuzzy } \\
\text { Membership }\end{array}$ & $\begin{array}{c}\text { Spatial Analyst / } \\
\text { Fuzzy Membership }\end{array}$ & $\begin{array}{c}\text { Spatial Analyst / } \\
\text { Fuzzy Membership }\end{array}$ & $\begin{array}{c}\text { Spatial Analyst / Fuzzy } \\
\text { Membership }\end{array}$ \\
\hline Input & declividade & Divide_uso & Divide_solos & Divide_MorfoE \\
\hline Parâmetro & MS Large; $1 ; 1 ;$ None & $\begin{array}{l}\text { MS Large; } 1 ; 1 ; \\
\text { None }\end{array}$ & $\begin{array}{l}\text { MS Large; } 1 ; 1 ; \\
\text { None }\end{array}$ & MS Large; $1 ; 1 ;$ None \\
\hline Output & FuzzyMe_declividade & FuzzyMe_Uso & FuzzyMe_solo & FuzzyMe_MorfoE \\
\hline \multicolumn{5}{|c|}{3 - Combinação das camadas } \\
\hline Ferramenta & \multicolumn{4}{|c|}{ Spatial Analyst / Overlay } \\
\hline Input & \multicolumn{4}{|c|}{ FuzzyMe_declividade; FuzzyMe_Uso; FuzzyMe_solo; FuzzyMe_MorfoE } \\
\hline Parâmetro & \multicolumn{4}{|c|}{ gamma; 0,9} \\
\hline Output & \multicolumn{4}{|c|}{ Vulnerabilidade } \\
\hline
\end{tabular}

Fonte: Lima (2017).

\section{RESULTADOS E DISCUSSÃO}

A discussão de vulnerabilidade e classificação dos riscos, feita a partir de cada uma das USEPs delimitadas, correlaciona os processos históricos e atuais na área de estudo sendo possível observar a diversidade de ambientes em cada unidade.

As noções de vulnerabilidade e risco aqui apresentadas estão relacionadas com as dinâmicas coletivas de processos e legados históricos em nível local a partir da compreensão da dimensão do habitar social, ou seja, essencialmente a presença de população diante da pertinência de algum tipo de agravo à vida humana (BRASIL, 2007; CARVALHO, 2010; LAVELL et al, 2012; LAYRARGUES, 2012; PORTO, 2012; SAITO et al, 2015; VEYRETE, 2015).

No âmbito da cidade são evidentes as vulnerabilidades em relação as chuvas, deslizamentos ou mesmo a relação saúde e território em que os processos de ocupação são evidenciados e expostos na medida em que essas paisagens urbanas ou rurais são transformadas, cenários esses que representam o contexto do atual ordenamento na região de Guaratiba.

A partir dessa abordagem, compreendemos a classificação de riscos socioecológicos sob a perspectiva do lugar, do cotidiano e dos atores participantes. Portanto, os riscos socioecológicos se constituem no contexto de vulnerabilidade que envolve os grupos sociais e seus ciclos de exposição e resposta aos eventos extremos que possam propiciar a ocorrência de agravos e doenças. Trata-se então de uma relação que envolve de maneira intrínseca a sociedade, os sistemas ecológicos e jurisdições vigentes a esses lugares, conforme conceito de sistemas socioecológicos. (GLASER, 2006)

Na seção seguinte, apresentamos a definição e caracterização das Unidades Socioecológicas da Paisagem à respectivas classificações de vulnerabilidade e riscos socioecológicos. 


\section{Unidades Socioecológicas da Paisagem}

Unidades de Paisagem são comumente empregadas em metodologias aplicadas em diagnósticos de paisagem ou estudos ambientais (ANDORRA, 2014; BARCELONA, 2018; FÁVERO et al, 2007; HOYUELA JAYO, 2016; 2017; MAGALHAES et al, 2016; SILVA et al, 2013; TUDOR, 2014). Portanto, entende-se pelos mapeamentos de Unidades de Paisagem como uma ferramenta capaz de avaliar potencialidades e fragilidades dessas áreas para reconhecer seus valores culturais (CUSTÓDIO, 2014; RIBEIRO, 2016), além de corroborar com os instrumentos jurídicos da Política Nacional de Meio Ambiente, Lei 6.938/81 (BRASIL, 1981).

Tendo em vista todo o arcabouço teórico e legal supracitado, a Unidade Socioecológica da Paisagem (USEP) reproduz unidades representadas por feições ou características homogêneas a partir do uso e cobertura do solo, propriedades físicas, bióticas, sociais, de serviços ambientais, seus simbolismos culturais e identificação de jurisdição institucional ou ausência da mesma, pois entende-se que os instrumentos legais são participantes dos processos históricos e colaboram no grau de transformação da paisagem (LIMA, 2017).

Nesse sentido, a área de estudo foi avaliada sob a ótica das USEPs que apresentam uma caracterização local e de cenário atual, para entendimento e compreensão de fatores relacionados a riscos.

A seguir as Figuras 4 e 5 delimitam os mapeamentos que representam as USEPs e modelagem de deslizamentos, para a classificação de vulnerabilidade e riscos socioecológicos.

Figura 4 - Unidades Socioecológicas da Paisagem

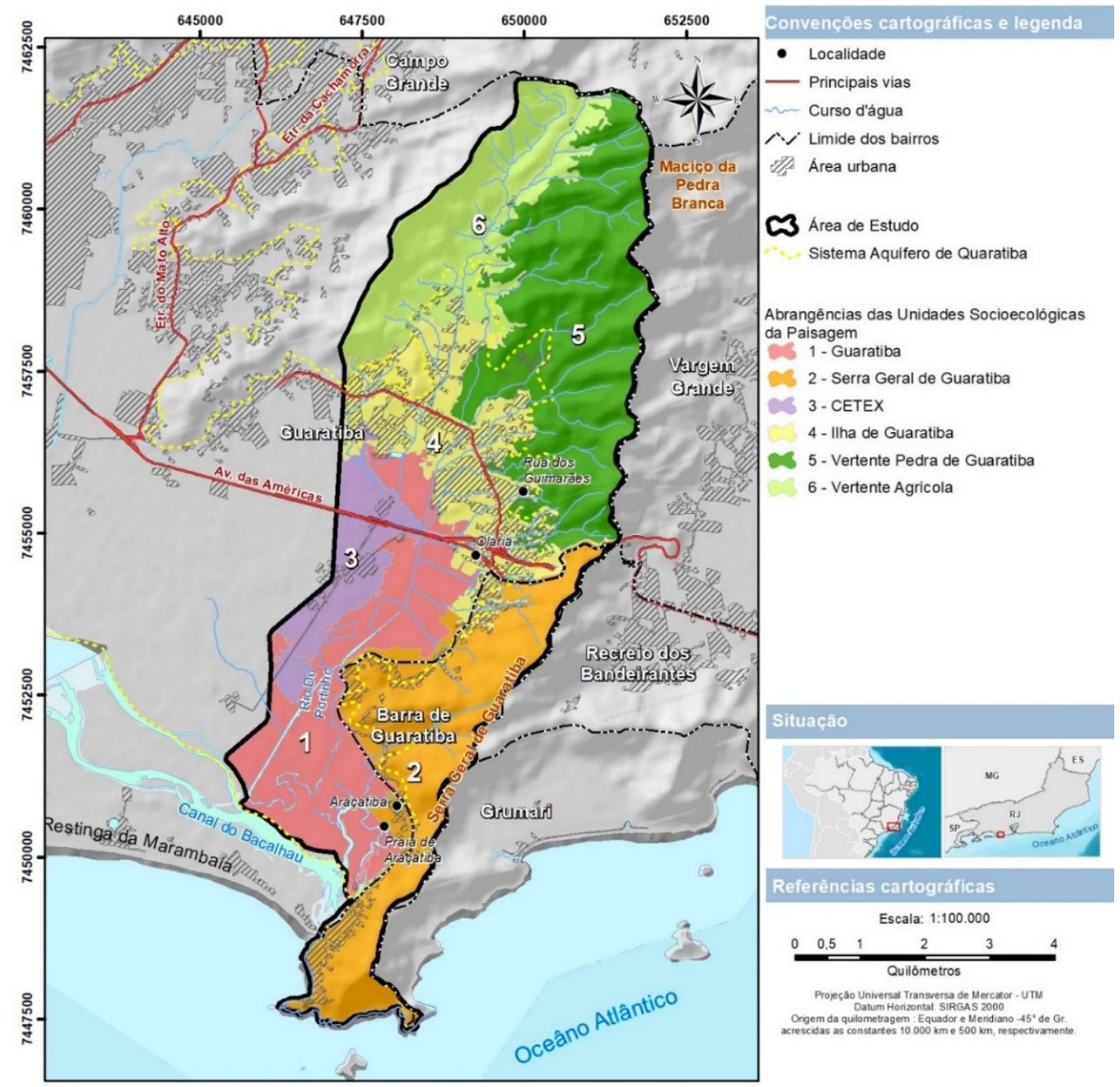

Fonte: Lima (2017).. 
Figura 5 - Áreas de Vulnerabilidade na Área de Estudo.

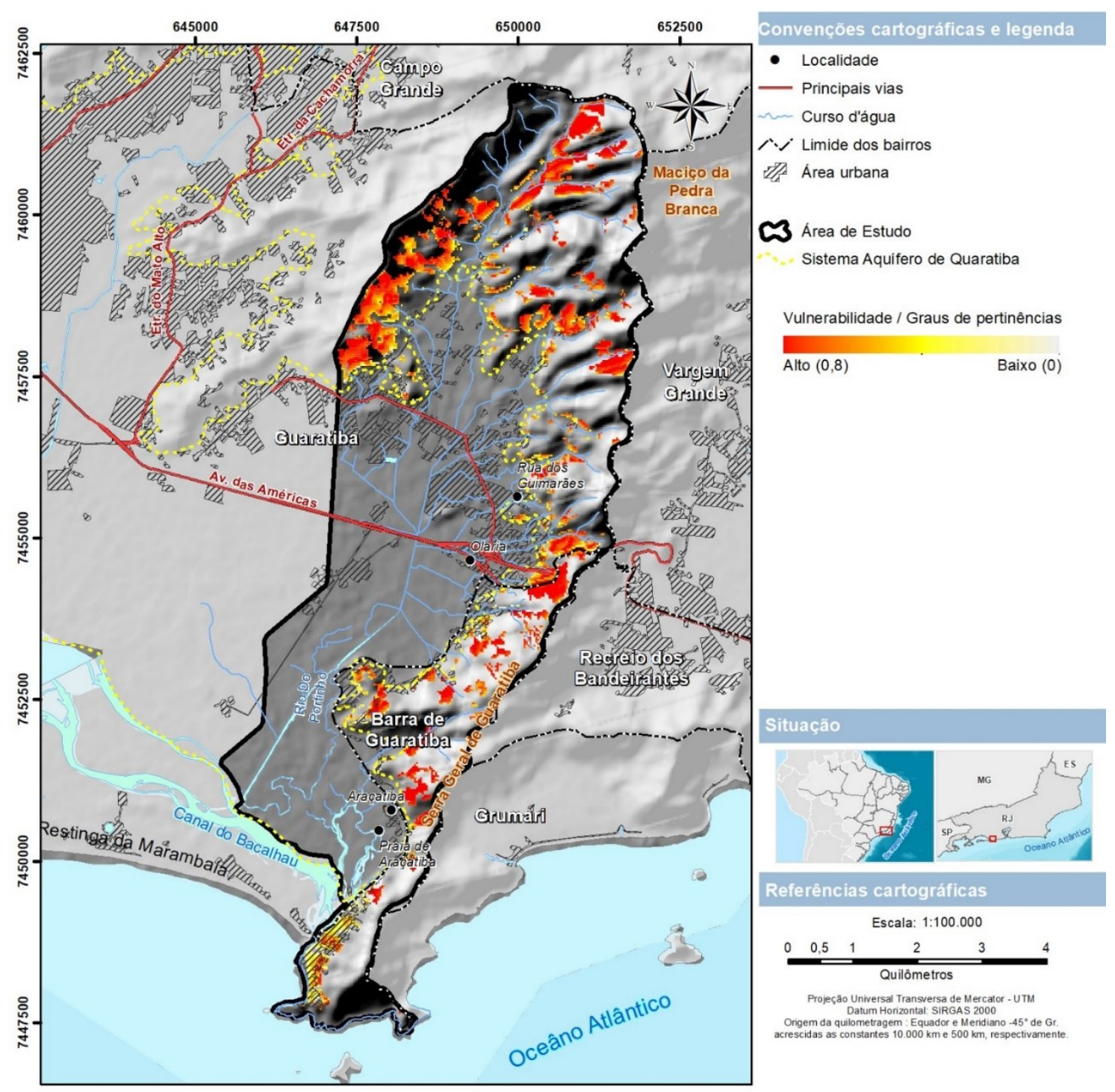

Fonte: Lima (2017).

$\mathrm{Na}$ caracterização das áreas de vulnerabilidade o resultado da modelagem por graus de pertinência variou entre 0 a 0,8 (Figura 5). Para definição qualitativa das áreas de risco de natureza de movimento de massa, foram assumidos valores entre 0,6 a 0,8 (áreas núcleo) e proximidade de áreas de influência urbana.

Os valores inferiores a 0,6 não representaram áreas núcleo na modelagem, sendo assim considerados de menor pertinência para áreas de risco.

Portanto, considerou-se na caracterização das áreas vulneráveis e de risco: 1) os graus de pertinência valores superiores a 0,$6 ; 2$ ) as áreas sujeitas a inundações (indicadas pela população de moradores); 3) e presença de mangue sobrepostas a ocupações humanas, conforme observado em campo.
Áreas que não apresentam pertinência a riscos

Nos trabalhos de campo pudemos constatar, in loco, que as dinâmicas espaciais relacionadas às USEPs 1 e 3 estão diretamente relacionadas ao contexto de áreas protegidas sob tutelas militar e estadual, ou seja, com restrições à ocupação humana, logo, por consequência dessas gestões, as paisagens estão ecologicamente mais conservadas.

Sob essa ótica as USEPs 1 e 3 (Figura 6) são unidades onde localmente não foram identificadas vulnerabilidades ou pertinências a eventos de risco analisados na modelagem ou informações coletadas a partir das entrevistas 
Figura 6 - Áreas que não apresentaram nenhum grau de pertinência a riscos socioecológicos.
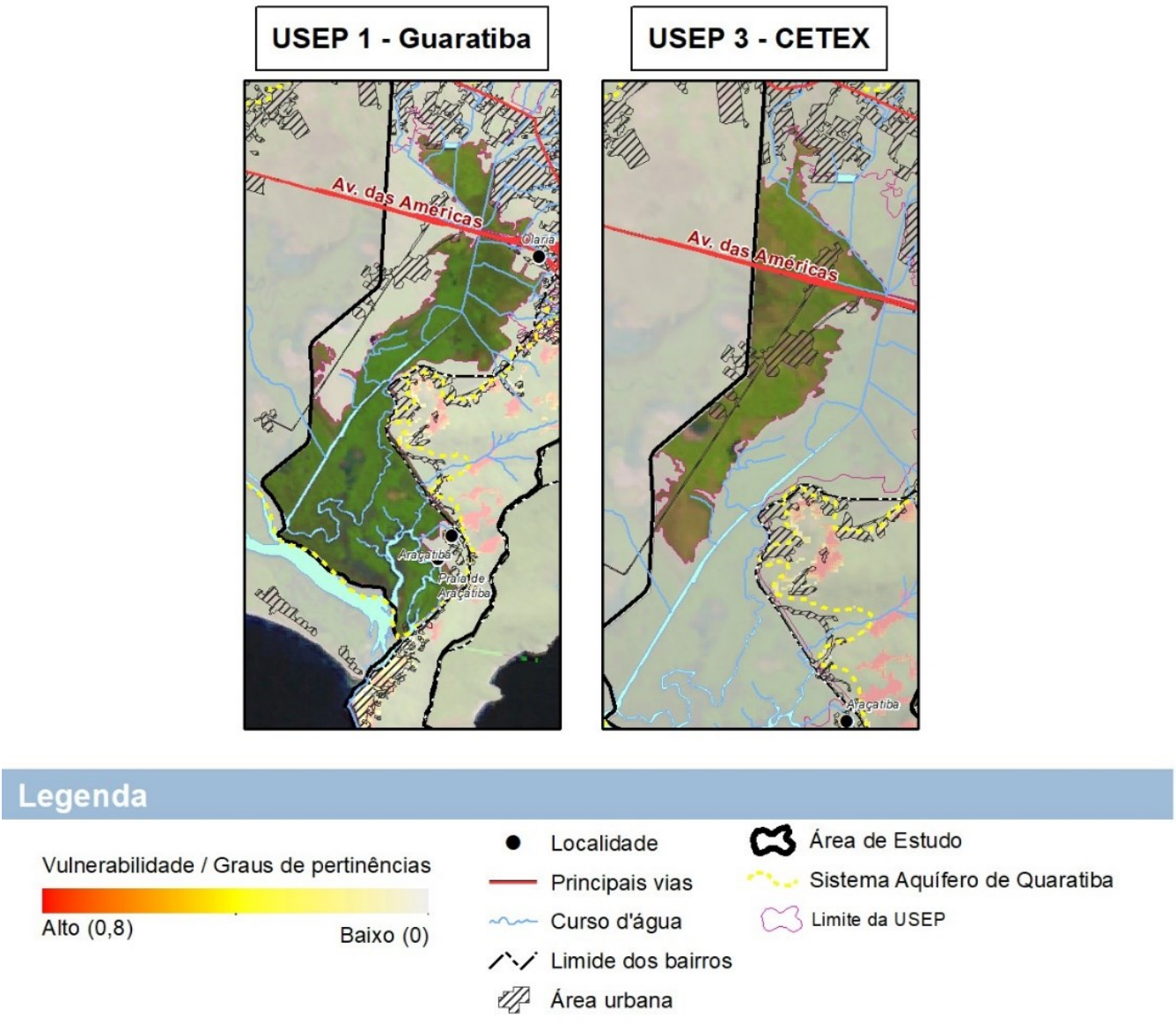

Fonte: Adaptado de Lima (2017).

USEP 1 - Guaratiba: Nessa unidade são predominantes ambientes de formações de mangue (77\%) e campos salinos (15\%). Área de relevo plano, com 0 a $10 \%$ de declividade e amplitude altimétrica de 0 a $32 \mathrm{~m}$. Abrangência de $99 \%$ em áreas protegidas por Jurisdição Estadual (REBIO Estadual de Guaratiba). Na cobertura da unidade as formações de mangue distribuindo-se por ambientes lacustres com influência permanente das marés. Na Unidade a influência urbana é menor que 1\% (ocorrem apenas no entorno).

USEP 3 - CETEX: Essa unidade abrange $100 \%$ de seus limites em áreas protegidas por Jurisdições Estadual, Municipal e área militar, portanto com restrições de ocupação urbana. O uso do solo na unidade corresponde a $36 \%$ de vegetação secundária, $36 \%$ de vegetação gramíneo-lenhosa, $12 \%$ de áreas urbanizadas (estruturas da base militar e um pouco do entorno), $12 \%$ de formação de mangue e $4 \%$ de campos salinos.

Áreas que apresentam pertinência a riscos

A seguir as unidades (Figura 7) onde a modelagem demonstra graus de pertinência entre 0,6 e 0,8 para riscos geomorfológicos, e a partir das análises qualitativas observadas em campo riscos de inundação e de saúde. 
Figura 7 -Áreas que apresentaram graus de pertinência a riscos socioecológicos.
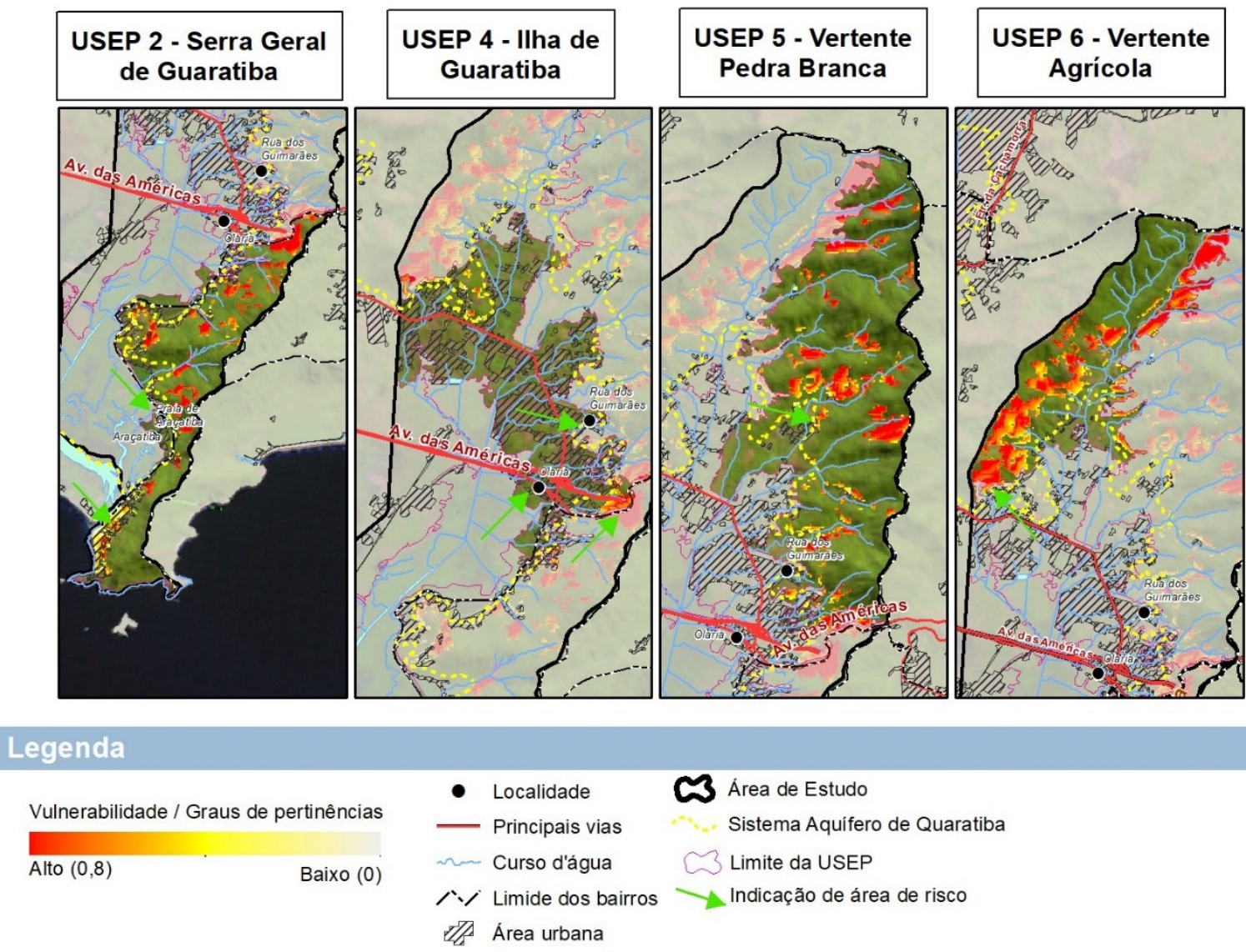

Fonte: Adaptado de Lima (2017).

USEP 2 - Serra Geral de Guaratiba: $\mathrm{Na}$ cobertura da unidade, predominam formações de vegetação secundária em relevo acidentado, com significativa influência urbana $(12 \%$ da unidade), inclusive sobre as formações de mangue. $\mathrm{O}$ relevo varia muito com amplitude altimétrica entre 1 e $469 \mathrm{~m}$. A abrangência corresponde a $94 \%$ de sobreposição com áreas protegidas de Jurisdições Estadual de proteção integral, ou seja, uso restrito (PE Estadual da Pedra Branca) e Municipal categorizada por proteção de uso sustentável (APA do Pedra Branca).

O uso do solo na unidade corresponde a $61 \%$ de vegetação secundária, $12 \%$ de áreas urbanizadas, $12 \%$ de vegetação arbóreoarbustiva, $8 \%$ de agricultura, $4 \%$ de vegetação gramíneo lenhosa, $2 \%$ de formação de mangue e $1 \%$ de afloramento rochoso.

Essa USEP faz parte do eixo de expansão demográfica da cidade do Rio de Janeiro, também interceptada pelos eixos: da Avenida Burle Marx (antiga estrada de Barra de Guaratiba), Avenida das Américas e implementação da via expressa e BRT TransOeste, inaugurada em 2012.
Considerando que tal via expressa é um importante eixo viário que interliga os bairros de Santa Cruz, Guaratiba, Recreio dos Bandeirantes e Barra da Tijuca. Tal desenvolvimento de infraestruturas viárias corresponde ao projeto dos grandes eventos esportivos alocados na cidade (Copa do mundo de 2014 e Jogos Olímpicos de 2016).

No entorno dos principais acessos rodoviários, existem alguns trechos de ocupações onde é possível observar a transição entre os limites do manguezal e áreas residenciais. Essas situações demonstram fragilidade no ordenamento territorial local, no que tange ao tema de habitação para populações vulnerabilizadas, expondo esses grupos a agravos acometidos por doenças infecciosas, que estão relacionadas a condicionantes ambientais, como leptospirose e dengue (CHAIBLICH, 2016; LIMA; CHAIBLICH, 2015), doenças que dependem de exposições precárias de saneamento e situações de alagamento, conforme pode ser observado no registro abaixo (Figura 8), um ambiente vulnerável no qual classificamos a pertinência a risco socioecológico do tipo biológico no contexto da saúde ambiental. 
Figura 8 - Área de colonização do mangue bem próximo de uma residência (USEP 2)

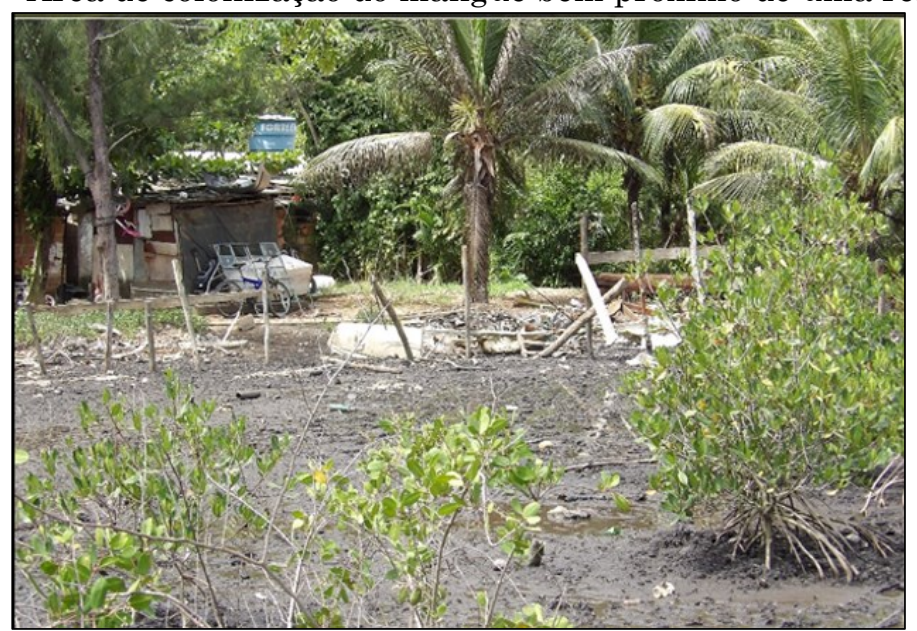

Foto: Juliana Valentim Chaiblich, dezembro de 2015.

$\mathrm{Na}$ localidade de Araçatiba, não existe um entendimento claro sobre a presença de riscos a partir da percepção dos moradores. Todavia, uma moradora relatou que, a cada 10 anos, acontecem eventos de influências das marés que inundam áreas próximas às residências. Aqui, a percepção de risco relatada pelos moradores está muito relacionada à discussão apresentada por Marandola (2014), que ressalta o sentimento de medo e incerteza como parte do cotidiano dos moradores, mais especificamente pela questão fundiária e eminente possibilidade de remoção.

Essa situação de medo é presente devido ao contexto de implantação da REBIO (com data de criação em 1974) e a existência dessas habitações. O exército realizou cadastramentos junto a Secretaria do Patrimônio da União (SPU) desde o início das primeiras ocupações em 1950. Anos depois, estas habitações estariam contidas em limites de uso restrito à Unidade de Conservação de proteção integral sob tutela estadual, não sendo possível a execução de obras de saneamento, intervenções ou melhorias. Portanto, os anseios, a insegurança e o medo giram em torno das perspectivas futuras de suas famílias e no cotidiano da população local.

USEP 4 - Ilha de Guaratiba: Unidade com sobreposição de $42 \%$ em áreas protegidas por Jurisdições Estadual e Municipal. O relevo é predominantemente plano, com amplitude altimétrica de $0-171 \mathrm{~m}$. $\mathrm{O}$ ambiente no entorno do mangue favorece ocorrências de inundação pelas características hidromórficas do terreno, além de estar completamente contida nos limites do aquífero de Guaratiba, ambiente sujeito a dinâmicas de encharcamento estacional.

Essa unidade se destaca pelo padrão espacial significativamente urbanizado (46\%), além da ocorrência de áreas produtivas que correspondem a $8 \%$ de agricultura, e demais usos de $28 \%$ de vegetação arbóreo-arbustiva, e $4 \%$ de vegetação secundária.

Assim como a USEP 2, essa unidade faz parte do eixo viário que interliga os bairros de Santa Cruz, Guaratiba, Recreio dos Bandeirantes e Barra da Tijuca, no contexto do desenvolvimento de infraestruturas da cidade do Rio de Janeiro para atendimento à demanda de transportes e locomoção da população para a realização dos grandes eventos esportivos.

Nessa unidade, também visitamos as localidades de Olaria e Rua dos Guimarães. Nesses locais, os moradores que abordamos relataram problemas com inundações de diferentes naturezas. Na Rua dos Guimarães, existe uma dinâmica de enchentes relacionadas às chuvas. Essa rua está localizada em terreno originalmente de confluência entre dois rios (nomes não identificados nas bases cartográficas). O nível da rua, cujo percurso é quase todo pavimentado, está acima do nível das residências. Observamos, em algumas entradas das casas, um tipo de beiral, construídos para prevenir as inundações dentro das casas.

Na localidade de Olaria, as inundações se dão principalmente pelas águas das chuvas que escorrem da Avenida das Américas. Os acessos transversais e residências também estão com nível abaixo da estrada principal devido à realização de obras de engenharia para a ampliação da referida avenida. Também foi relatado por duas moradoras entrevistadas que entre os anos de 2015 e 2016, houve notificações de dengue entre moradores da localidade de Olaria. Ou seja, acrescida ao risco de inundação, existe a sujeição de vulnerabilidade por parte da população em decorrência da proliferação de vetores de doenças transmitidas por mosquitos, como a dengue. 
Nessa área, vale destacar um evento histórico, ocorrido em abril de 2010 (Figura 9), e que consta nos registros dos 50 maiores acidentes geológicos-geotécnicos na cidade do Rio de Janeiro no período de 1966 e 2016, sendo um escorregamento de alta magnitude na
Estrada da Grota Funda, no bairro de Guaratiba. Área em que a modelagem apresentou valores de alta pertinência, portanto, atenção para risco socioecológico do tipo de deslizamento.

Figura 9 - Registro fotográfico do escorregamento na Estrada da Grota Funda em abril de 2010

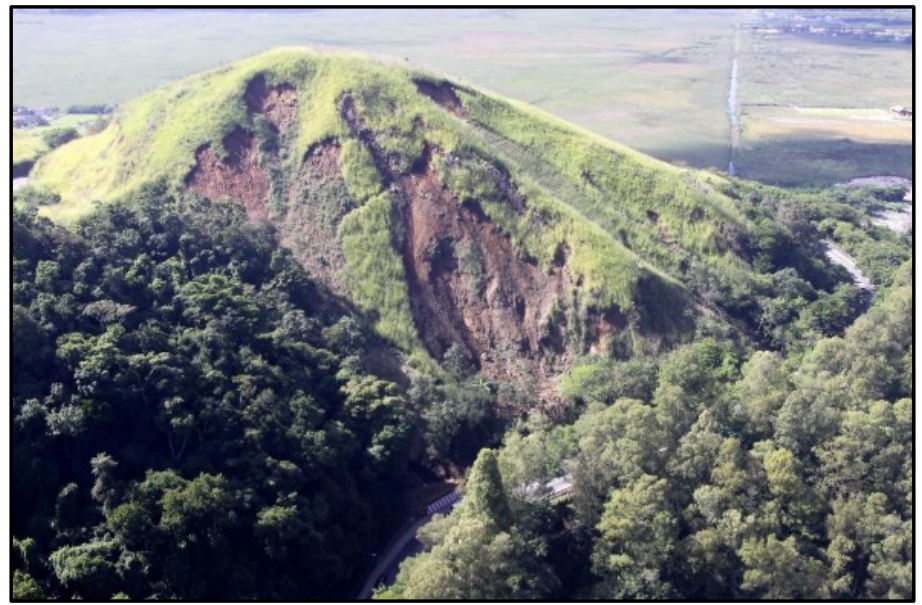

Fonte: GEO-RIO (2016).

USEP 5 - Vertente Pedra Branca: A unidade faz sobreposição com $59 \%$ de áreas protegidas por Jurisdição Estadual. Na cobertura da unidade, predominam formações de vegetação secundária, com presença marcante de plantação de banana (agricultura) e pastagens (veg. gramíneo-lenhosa); no seu entorno é baixa a influência urbana (1\%). A amplitude altimétrica varia entre $6 \mathrm{~m}$ e $680 \mathrm{~m}$, um padrão de relevo marcado pela morfologia das planícies e abruptamente pelo Maciço da Pedra Branca.

O uso do solo apresenta os quantitativos de $70 \%$ em formação de vegetação secundária, 11\% de agricultura, $10 \%$ de vegetação gramíneolenhosa e $9 \%$ de vegetação arbóreo-arbustiva.

Nessa unidade, as manchas que indicam pertinências a eventos de risco, condizem com a situação de relevo acidentado, ou seja, áreas de alta pertinência de movimento de massa se sobrepondo com limites de áreas urbanas em amplitude altimétrica que varia em torno dos $30 \mathrm{~m}$, caracterizando, portanto, atenção a eventos de riscos socioecológicos relacionados com a dinâmica geomorfológica.

A partir dos $100 \mathrm{~m}$ de altitude, estabelecemse os limites do Parque Estadual, cujo mapeamento de uso e ocupação das terras não apresenta áreas urbanizadas; por conseguinte, as manchas da modelagem que indicam atenção para a situação do terreno não são consideradas como áreas de risco.
USEP 6 - Vertente Agrícola: Unidade localizada na encosta do maciço da Pedra Branca, com níveis altimétricos entre 13 e 498m; abrange $60 \%$ em áreas protegidas por Jurisdição Estadual. $\mathrm{Na}$ cobertura da unidade, predominam formações de vegetação secundária; presença significativa de atividades agrícolas (banana e plantação de espécies ornamentais); baixa influência urbana (aproximadamente $2 \%$ ).

Predominam as formações florestais com $40 \%$ de vegetação secundária, $24 \%$ de agricultura, incluindo cultivos ornamentais, $21 \%$ de vegetação arbóreo-arbustiva, $8 \%$ de vegetação gramíneo-lenhosa e $5 \%$ de floresta ombrófila.

A noroeste da bacia, não há áreas que indiquem habitações sobrepostas com as manchas apresentadas pela modelagem, porém há áreas urbanas ocupando terrenos com amplitude altimétrica entre 15 e $60 \mathrm{~m}$, que estão bem no entorno de áreas com maiores pertinência a risco geomorfológicos de deslizamento.

\section{CONSIDERAÇÕES FINAIS}

A delimitação das USEPs nos possibilitou compreender a diversidade de ambientes e matriz de heterogeneidade espacial, uma 
importante análise no entendimento dos contextos de riscos espacialmente localizados e dinâmicas sociais atuais das paisagens guaratibenses da área de estudo.

Esse mapeamento refletiu áreas com similaridades para cada unidade, a partir das escalas apresentadas e os processos históricos de uso e ocupação, etapa importante na abordagem integrada de vulnerabilidade e risco e da compreensão das interações socioecológicas existentes, como as habitações e sua convivência com as áreas protegidas. Situação que imbrica com os processos de crescimento da região, possíveis situações de vulnerabilidade e riscos e conflitos ambientais, a exemplo das habitações existentes no território da REBIO (localidade de Araçatiba), as quais passam por precariedades em virtude de estarem em território de jurisdição estadual de uso restrito.

É relevante, considerar a importância de uso de Sistemas de Informação geográfica e técnicas de geoinformação na avaliação de áreas de risco, sublinhando o método fuzzy adotado para este estudo, o qual permite uma avaliação mais precisa quando analisados os valores de alta pertinência no contexto desse estudo. Destaca-se o registro da figura 9 que infere um fenômeno de alta magnitude no histórico de eventos de risco na cidade do Rio de Janeiro.

A modelagem apresentada contribuiu muito para uma avaliação dos eventos de risco de natureza geomorfológica. As demais interpretações baseadas numa análise ambiental e esforços do levantamento de campo e conhecimento da região. Vale ressaltar a importância de ampliar as análises baseadas em métodos fuzzy na geração de áreas de alagamento, tendo em vista que essas áreas não foram geradas para fins da pesquisa realizada, sendo esta, uma questão muito crítica na região de Guaratiba.

Portanto, o presente estudo expõe como principais resultados dos processos de vulnerabilidade e riscos socioecológicos, que as classificações mais relevantes são voltadas à saúde ambiental e físicas relacionadas às dinâmicas de enchentes localizadas nas USEP2 e USEP 4; e dinâmicas geomorfológicas para habitações próximas às áreas declivosas nas USEP 2, USEP 4, USEP 5 e USEP6. Vale ressaltar as USEPs 2 e 4 , no sentido de uma fragilidade no planejamento urbano local no que diz respeito à ocupação sob as condições físicas nesses ambientes: relevo acentuado e características hidromórficas do terreno, além das situações de conflitos de interesses territoriais em Araçatiba, assim como a ocorrência de agravos e doenças que condicionam vulnerabilidade e riscos para a população local.

Diante do contexto supracitado, merece um destaque o elemento percepção na avaliação de áreas e populações vulneráveis devido a respectiva complexidade do tema. No âmbito das análises de risco, não se tratando apenas de considerar ambientes físicos e eventos ambientais, mas também, a natureza dos anseios vividos nesses habitats que sugerem riscos ou situações de perigo para essas populações e consequente fragilidade nas atuais políticas públicas voltadas para tais emergências. Sob essa ótica, considerar uma abordagem qualitativa e a historicidade das ocupações nesses estudos, contribui para a identificação de resultados relevantes junto à análise da percepção da população local, como um elemento importante, e talvez, necessário nas abordagens holísticas das avaliações de vulnerabilidade e risco voltadas para o planejamento urbano local.

\section{AGRADECIMENTOS}

As autoras e autores agradecem ao Instituto Estadual do Ambiente do Estado do Rio de Janeiro (INEA) e a Secretaria Municipal de Meio Ambiente do Rio de Janeiro (SMAC), pelas autorizações, apoio dos trabalhos de campo e disponibilidade de dados públicos para o desenvolvimento da pesquisa de mestrado que resultou os dados deste estudo. Agradecemos também pelas fotografias cedidas de acervos de pesquisa de Juliana Valentim Chaiblich. E por fim, pela contribuição dos avaliadores anônimos que contribuíram para a qualidade crítica na aprovação dessa publicação.

\section{REFERÊNCIAS}

\section{ANDORRA. La planificació del paisatge en} l'àmbit local a Europa. Els casos d'Alemanya, França, els Països Baixos, el Regne Unit, Suïssa i la regió de Valònia, a Bèlgica. Edició a cura de Pere Sala, Laura Puigbert i Gemma Bretcha. - Olot: Observatori del Paisatge de Catalunya; Govern d'Andorra. - p.; cm. - (Documents; 2). 2014. Disponível em: < http://www.catpaisatge.net/esp/documentacio_ doc_2.php>. Acesso em 05 jan. 2020.

BARCELONA - Gobierno de Barcelona. Observatorio del Paisaje de Cataluña. Los 
catálogos de paisaje de Cataluña: Metodología (Documents; 3)/ Joan Nogué, Pere Sala, Jordi Grau. - Olot: Observatorio del Paisaje de Cataluña; Barcelona: ATLL, 2018. Disponível em:

$<$

http://www.catpaisatge.net/esp/documentacio_ doc_3.php >. Acesso em: 05 jan. 2020.

BRASIL. Ministério das Cidades / Instituto de Pesquisas Tecnológicas - IPT. CARVALHO C. S.; MACEDO, E. S. de; OGURA, A. T. (Org.). Mapeamento de Riscos em Encostas e Margem de Rios / - Brasília: Ministério das Cidades; Instituto de Pesquisas Tecnológicas IPT, 2007 (176 p).

BRASIL. Lei $\mathrm{n}^{\circ}$ 6.938, de 31 de agosto de 1981.

Dispõe sobre a Política Nacional do Meio Ambiente, seus fins e mecanismos de formulação e aplicação, e dá outras providências. Diário Oficial [da] República Federativa do Brasil: seção 1, Brasília, DF, n. 167, p. 16.509, 2 set. 1981. Disponível em: $<$ http://www.planalto.gov.br/ccivil_03/LEIS/L 6938.htm>. Acesso em: 15 out. 2016.

CARVALHO, D. W. de. A Tutela Constitucional do Risco Ambiental. In: Estado de Direito Ambiental: Tendências. Organizadores: José Rubens Morato Leite, Heline Sivini Ferreira, Larissa Verri Boratti. - $2^{\mathrm{a}}$ ed. - Rio de Janeiro: Forense Universitária, 2010 (p. 261-282).

CHAIBLICH, J. V.. Estudo das vulnerabilidades socioambientais associadas à leptospirose no Município do Rio de Janeiro: Técnicas de Análise Espacial. - 2016. Dissertação (Mestrado em Saúde Coletiva) - Universidade Federal Fluminense, Rio de Janeiro, RJ, 2016.

CHRISTOFOLETTI, A.. Roteiro pelas proposições sobre paisagens. In: Modelagem de sistemas ambientais. $1^{a}$ edição - São Paulo: Editora Edgard Blucher Ltda, 1999.

CUSTÓDIO, M. M.. Introdução ao Direito de Paisagem: Contribuições ao seu reconhecimento como ciência no Brasil. 2014 - Rio de Janeiro: Lumen Juris, 2014 (385 p.).

EMBRAPA - Empresa Brasileira de Pesquisa Agropecuária. Sistema Brasileiro de Classificação de Solos. SANTOS, Humberto Gonçalves; JACOMINE, Paulo Klinger Tito; ANJOS, Lúcia Helena Cunha dos; OLIVEIRA, Virlei Álvaro de; LUMBRERAS, José Francisco; COELHO, Maurício Rizzato; ALMEIDA, Jaime Antonio de; CUNHA, Tony Jarbas Ferreira; OLIVEIRA, João Bertoldo de. 3ed. ver. Ampl. - Brasília, DF: Embrapa, 2013. $353 p$.

FÁVERO, O. A.; NUCCI, J. C.; DE BIASI, M.. Unidades de Paisagem e Zoneamento
Ambiental: subsídios para a gestão da Floresta Nacional de Ipanema - Iperó/SP. RA'EGA - O Espaço Geográfico em Análise, Curitiba, n. $14, \quad$ p. $35-53, \quad 2007$. http://dx.doi.org/10.5380/raega.v14i0.6814

FERNANDEZ, G. B.. Geomorfologia. In: Serra, MV; Serra, Maria Teresa F. Guia de História Natural do Rio de Janeiro. Rio de Janeiro: Editora Cidade Viva, 2012.

FERREIRA, M. C.. Iniciação à análise geoespacial: teoria, técnicas e exemplos para geoprocessamento. - $1^{\text {a }}$ ed. - São Paulo: Editora Unesp, 2014.

GEO-RIO - Fundação Instituto de Geotécnica do Município do Rio de Janeiro - GEO-RIO. Os 50 maiores acidentes geológicogeotécnicos na cidade do Rio de Janeiro entre 1966 e 2016. D'ORSI, Ricardo Neiva; PAES, Nelson Martins; MAGALHÃES, Marcelo Aldaher; SILVA JUNIOR, Luciano Reis da; VALENTE, Luiz Ricardo Schiavinato. Diretoria de Estudos e Projetos Gerência de Programas Especiais. 2016. Disponível em: $<$ http://alertario.rio.rj.gov.br/wpcontent/uploads/2016/12/PDF_ESTRUTURADO-LIVRETO_50-MAIORES-ACIDENTES-

A5.pdf>. Acesso em jan. 2017.

GLASER, M.. The Social Dimension in Ecosystem Management: Strengths and Weaknesses of Human-Nature Mind Maps. Human Ecology Review, Vol. 13, nº 2, 2006, Society for Human Ecology, p. 122-142. Disponível em: < http://www.humanecologyreview.org/pastissu es/her132/glaser.pdf>. Acesso em: 28 mar. 2016.

HOYUELA JAYO, J. A.. El Plan Director del Parque Municipal como modelo de planificación sostenible del paisaje en el corazón de la ciudad de Belo Horizonte. VIII Congreso Internacional de Ordenación del Territorio. Congreso de Derecho Urbanistico. 2016. 19p. Disponível em: < https://www.academia.edu/29958601/El_Plan _Director_del_Parque_Municipal_como_model o_de_planificaci\%C3\%B3n_sostenible_del_pai saje_en_el_coraz\%C3\%B3n_de_la_ciudad_de_ Belo_Horizonte $>$. Acesso em: 15 ago. 2017.

HOYUELA JAYO, J. A.. A Paisagem como Instrumento para um Planejamento Sustentável: uma visão dialética entre a Europa e o Brasil. In: Direito e Paisagem: a afirmação de um direito fundamental individual e difuso. OLIVEIRA, Marcio Luis de; CUSTÓDIO, Maraluce Maria; LIMA, Carolina Carneiro [Org.] - Belo Horizonte: Editora D'Plácido, 2017 (p. 39-76).

INEA - Instituto Estadual do Ambiente. O estado do ambiente: indicadores 
ambientais do Rio de Janeiro - 2010. Julia Bastos e Patricia Napoleão (Org.). - Rio de Janeiro (Estado). Secretaria Estadual do Ambiente. Rio de Janeiro: SEA; INEA, 2011.

LAVELL, A.; OPPENHEIMER, M.; DIOP, C.; HESS, J.; LEMPERT, R.; LI, J.; MUIR-WOOD, R.; MYEONG, S.; MOSER, S.; TAKEUCHI, K.; CARDONA， O.-D.; HALLEGATTE, S.; LEMOS, M.; LITTLE, C.; LOTSCH, A.; WEBER, E.. Climate Change: New Dimensions in Disaster Risk, Exposure, Vulnerability, and Resilience. In: Managing The Risks Of Extreme Events And Disasters To Advance Climate Change Adaptation.: a special reporto f Working Groups I and II. Cambridge: Cambridge University Press, 2012 (p. 25-64).

LAYRARGUES, P. P.. Educação para Gestão Ambiental: a cidadania no enfrentamento político dos conflitos socioambientais. In: Sociedade e Meio Ambiente: a educação ambiental em debate. LOUREIRO, C. F.; LAYRARGUES, P. P.; CASTRO, R. S. de (Organizadores). $-7^{\mathrm{a}}$ ed., - São Paulo: Cortez, 2012 (p. 89-156).

LIMA, M. L. da S.; CHAIBLICH, Juliana Valentim. Análise Geo-Espacial da Dengue no Município do Rio de Janeiro (RJ). In: Anais do $\mathbf{1 1}^{\circ}$ Congresso Brasileiro de Saúde Coletiva. Goiânia (GO). 2015.

LIMA, M. L. da S.. Vulnerabilidade e Riscos Socioecológicos no Sistema Hidrográfico do Rio do Portinho, Região de Guaratiba no Município do Rio de Janeiro (RJ). Dissertação (Mestrado em geografia) Pontifícia Universidade Católica do Rio de Janeiro, Rio de Janeiro, RJ, 2017.

MAGALHÃES, V. L.; CUNHA, J. E. da; NÓBREGA, M. T. de. Caracterização Morfopedológica de Unidades de Paisagem do Extremo Oeste do Paraná. Perspectiva Geográfica-Marechal Cândido Rondon, Ed. Esp., v.11, n.15, jul.-dez., 2016. p. 245-253.

MANSUR, A. L.. O velho oeste carioca História da ocupação da Zona Oeste do Rio de Janeiro (de Deodoro a Sepetiba), do século XVI aos dias atuais. $-1^{\mathrm{a}} \mathrm{ed}$. - Rio de Janeiro: Ibis Libris, 2008.

MANSUR, A. L.. O velho oeste carioca Volume II - Mais histórias da ocupação da Zona Oeste do Rio de Janeiro (de Deodoro a Sepetiba), do século XVI ao XXI. - $1^{\mathrm{a}} \mathrm{ed}$. Rio de Janeiro: Ibis Libris, 2011.

MANSUR, A. L.. O velho oeste carioca Volume III - Outras histórias da ocupação da Zona Oeste do Rio de Janeiro (de Deodoro a Sepetiba), do século XVI ao XXI. - $1^{\mathrm{a}}$ ed. - Rio de Janeiro: Ibis Libris, 2016.
MARANDOLA JÚNIOR, E.. Habitar em risco: mobilidade e vulnerabilidade na experiência metropolitana. - São Paulo: Blucher, 2014.

MOTA, M. S. C.. Nas terras de Guaratiba. Uma aproximação histórico-jurídica às definições de posse e propriedade da terra no Brasil entre os séculos XVI-XIX. 2009 (334 f). Orientador: María Verónica Secreto de Ferreras. Tese (Doutorado) Universidade Federal Rural do Rio de Janeiro, Instituto de Ciências Humanas e Sociais.

PORTO, M. F. de S.. Uma ecologia política dos riscos: princípios para integrarmos o local e o global na promoção da saúde e da justiça ambiental. Rio de Janeiro: Editora FIOCRUZ, 2012 (270 p.).

REIS, A. P. dos; MANSUR, K. L.. Sinopse Geológica do Estado do Rio de Janeiro. Mapa Geológico 1:400.000. Secretaria de Estado de Meio Ambiente - Departamento de Recursos Minerais - Diretoria Técnica- Niterói, 1995.

RIBEIRO, S. C.. Etnogeomorfologia na Perspectiva da Gestão Ambiental e Aprendizagem na Educação Básica. Espaço Aberto, PPGG - UFRJ, V. 6, N.1, p. 175-190, 2016.

https://doi.org/10.36403/espacoaberto.2016.52 42 Disponível em: < https://revistas.ufrj.br/index.php/EspacoAbert o/article/view/5242/3850>. Acesso em: 8 nov. 2018.

SAITO, S. M.; SORIANO, É.; LONDE, L. de R.. Desastres Naturais. In: Sensoriamento Remoto para desastres naturais. SAUSEN, T. M.; LACRUZ, M. S. P. (Org.) - São Paulo: Oficina de Textos, 2015 (p. 23-40).

SECRETARIA DE MEIO AMBIENTE DO RIO DE JANEIRO - SMAC. Mapeamento da Cobertura Vegetal e do Uso das Terras do Município do Rio de Janeiro (2011) - Sig Floresta. Rio de Janeiro. Disponível em: $<$ http://www.rio.rj.gov.br/web/smac/sig-

floresta>. Acesso em: outubro de 2015.

SILVA, J. M. P.; MANETTI, C.; TÂNGARI, V.. Compartimentos e Unidades de Paisagem: método de leitura da paisagem aplicado à linha férrea. Paisagem e ambiente: ensaios - $n$. 31 - São Paulo - p. 61 - 80 - 2013. https://doi.org/10.11606/issn.2359-

5361.v0i31p61-80

SOLÓRZANO, A.; LAZOS-RUÍZ, A. E.; OLIVEIRA, R. R. de. Landscape Reading of Urban Forests in Rio de Janeiro: Interpreting Past and Current Socioecological Interactions. HALAC. Guarapuava, volumen VI, número 1, enero-junio 2016, p. 211-224. https://doi.org/10.5935/2237-2717.20160011 
TUDOR, C.. An Approach to Landscape

Character Assessment. Natural England, October, 2014. Disponível em: < https://assets.publishing.service.gov.uk/gover nment/uploads/system/uploads/attachment_d ata/file/691184/landscape-character-

assessment.pdf >. Acesso em 9 nov. 2019.

VEYRETE, Y. (Org.). Os riscos: o homem como agressor e vítima do meio ambiente. $2^{\mathrm{a}}$ ed., $1^{\mathrm{a}}$ reimpressão. - São Paulo: Contexto, 2015.

ZADEH, L. A.. Fuzzy Set as a Basis for a Theory of Possibility. Fuzzy Sets and Systems 1, 1978 (p. 3-28).

ZADEH, L. A.. Fuzzy sets. Information and Control, v. 8, p. 338-353, 1965.

\section{CONTRIBUIÇÃO DOS AUTORES}

Maria Luciene da Silva Lima concebeu o estudo, executou trabalhos de campo, analisou dados e redigiu o texto. Alexandro Solórzano foi orientador da pesquisa, participou dos trabalhos de campo e contribuiu com a revisão acadêmica como um todo e redação do texto. Luiz Felipe Guanaes Rego foi coorientador da pesquisa, contribuiu com a revisão metodológica da pesquisa e redação do texto com especialidade em Sistema de Informação Geográfica. Marcelo Motta de Freitas foi colaborador, participando dos trabalhos de campo, caracterização da área de estudo e redação do texto com especialidade em geografia física. Bianca Pereira Alvim Porto foi colaboradora da pesquisa, contribui com as análises de dados, revisão crítica e redação do texto com especialidade em saúde ambiental e vulnerabilidade. 